\title{
A Water-saving I rrigation Decision-making Model for Greenhouse Tomatoes based on Genetic Optimization T-S Fuzzy Neural Network
}

\author{
Zhili Chen ${ }^{1,2}$, Chunjiang $\mathrm{Zhao}^{2,3 *}$, Huarui $\mathrm{Wu}^{2,3}$, Yisheng Miao ${ }^{2,3}$ \\ 1College of Information and Electrical Engineering, China Agricultural University, Beijing, China \\ 2National Engineering Research Center for Information Technology in Agriculture, Beijing, China \\ [e-mail: chenzhili@nercita.org.cn]
}

3Beijing Research Center for Information Technology in Agriculture, Beijing Academy of Agriculture and

Forestry Sciences, Beijing, China

[e-mail: zhaocj@nercita.org.cn, wuhuarui1975@163.com, miaoys@nercita.org.cn]

*Corresponding author: Chunjiang Zhao

Received January 24, 2018; revised April 19, 2018; revised June 19, 2018; accepted October 28, 2018;

Published June 30, 2019

\begin{abstract}
In order to improve the utilization of irrigation water resources of greenhouse tomatoes, a water-saving irrigation decision-making model based on genetic optimization T-S fuzzy neural network is proposed in this paper. The main work are as follows: Firstly, the traditional genetic algorithm is optimized by introducing the constraint operator and update operator of the Krill herd (KH) algorithm. Secondly, the weights and thresholds of T-S fuzzy neural network are optimized by using the improved genetic algorithm. Finally, on the basis of the real data set, the genetic optimization T-S fuzzy neural network is used to simulate and predict the irrigation volume for greenhouse tomatoes. The performance of the genetic algorithm improved T-S fuzzy neural network (GA-TSFNN), the traditional T-S fuzzy neural network algorithm (TSFNN), BP neural network algorithm(BPNN) and the genetic algorithm improved BP neural network algorithm (GA-BPNN) is compared by simulation. The simulation experiment results show that compared with the TSFNN, BPNN and the GA-BPNN, the error of the GA-TSFNN between the predicted value and the actual value of
\end{abstract}

This work is supported by Beijing Natural Science Foundation (4172024). 
the irrigation volume is smaller, and the proposed method has a better prediction effect. This paper provides new ideas for the water-saving irrigation decision in greenhouse tomatoes.

Keywords: T-S fuzzy neural network, genetic optimization, krill herd, irrigation decision, greenhouse tomatoes, Internet of Things

\section{Introduction}

The annual agricultural water consumption accounts for 65 percent of the country's total water consumption in China and the utilization rate of water resources in greenhouse is generally low [1]. In the process of tomatoes growth and development in greenhouse, there are many large leaves and the transpiration coefficient is high. Therefore, the water consumption is large. In addition, the water management in greenhouse vegetables production in China lacks scientific quantitative indicators, and water irrigation is unreasonable and unscientific [2]. In order to increase production, farmers are mainly experienced in irrigation and high-yield irrigation in the production process, resulting in serious waste of water resources, and also accompanied by problems such as soil salinization, aggravation of diseases and insect pests, decline in the quality of tomatoes, and decline in yield, and etc [3]. The volume of irrigation and irrigation time directly affect the growth, development, yield, quality, and soil environment of the vegetables. Therefore, the realization of precise water-saving irrigation plays a crucial role in greenhouse tomatoes [4].

Agricultural IoT monitors the agricultural production environment by using a large number of sensor nodes to form a monitoring network in the agricultural production process, which provides a strong basis for scientific production and analysis. Wireless sensor network (WSN) is an important means to solve the problem of agricultural information perception to obtain the "last mile". The current facility intelligent decision-making for water-saving irrigation of tomatoes is mainly calculated by referring to the crop evapotranspiration $\left(\mathrm{ET}_{0}\right)$ [5], However, this method requires high accuracy for the collected environment data of the Internet of Things (IoT), and the error of the calculation result is also relatively large. It can't meet the real-time demand of precision irrigation.

Based on the analysis of relevant factors affecting the irrigation volume and the original calculation $\mathrm{ET}_{0}$ method, we find that the irrigation volume has a strong relationship with the growth stage of crops, inside solar radiation, the temperature and humidity of soil, the temperature and humidity of air and other factors, so the water-saving irrigation technology is a typical multi-factor decision problem. Although these factors have specific values, they 
also have certain fuzzy attributes. The fuzzy neural network has the advantages of handling uncertain, non-linear, ill-posed problems and the advantages of parallel computing and adaptive learning. Compared with the traditional irrigation calculation method, the fuzzy neural network has better performance and it can better achieve the goal of precision irrigation [6].

Therefore, combining fuzzy theory with neural network, this paper puts forward a water-saving irrigation decision-making model based on genetic optimization T-S fuzzy neural network for greenhouse tomatoes. This method overcomes the problem of low accuracy in fuzzy system, and is more efficient than the system which only uses the artificial neural network (ANN). The real-time environmental data such as inside solar radiation, air temperature and humidity, soil temperature and humidity is collected by the Internet of Things in greenhouse. Combined with information on current tomatoes' growth and development stages, etc., the demand pattern and influencing factors of greenhouse tomatoes under regulated deficit irrigation conditions are analyzed. Based on T-S fuzzy neural network, a water-saving irrigation decision-making model for greenhouse tomatoes, called GA-TSFNN, is constructed. Above all, the constraint operator and update operator of the Krill herd $(\mathrm{KH})$ algorithm [7] are used to optimize the traditional genetic algorithm. Subsequently, the weights and thresholds of T-S fuzzy neural network are optimized by using the improved genetic algorithm. Finally, the GA-TSFNN is used to simulate and predict the irrigation volume for greenhouse tomatoes. It optimized the weights and thresholds of fuzzy neural network, thus implemented precise irrigation. It makes the soil always stay in the most appropriate humidity state and it is designed to keep the tomatoes of high and stable yield at the same time, through the scientific and reasonable water-saving irrigation management, finally it can achieve the goal of saving energy and water, environmental protection, and raising the quality of vegetables.

The rest of the paper is organized as follows. The research status of water-saving irrigation for greenhouse tomatoes in domestic and foreign countries is introduced in Section 2. The relevant theories of fuzzy neural network, the influencing factors of water-saving irrigation and a water-saving irrigation decision-making model for greenhouse tomatoes based on T-S fuzzy neural network using an improved genetic algorithm are proposed in Section 3. Subsequently, the simulation experiments and results analysis are provided in Section 4. Finally, the conclusion and the direction of future research work are provided in Section 5.

\section{Related work}

In the process of vegetable growth and development, the water requirement at the seedling stage is relatively small, and the amount of water during the product organ formation is relatively large. This is also the critical period of vegetable water demand. At this time, water shortage has a greater impact on the yield and quality. The change in the actual water 
consumption of crops is affected by various environmental factors such as light, temperature, soil texture, etc.

Liu et al. [8] found that the water requirement of greenhouse tomatoes is shown in the early stage, in the medium term, and in the later period when the change rule is first increased and then reduced. The peak water requirement occurs in the flowering and fruit setting period and the early mature harvesting. There is a linearly positive correlation between tomatoes water requirement and solar radiation, air temperature and saturation, and a linearly negative correlation with relative humidity and a linearly positive correlation with leaf area index. The tomatoes water requirement in greenhouse is affected by the meteorological factors and its own growth and development status. Kumar et al. [9] found that water stress significantly affected tomato dry matter accumulation and total soluble solids content. Water stress occurred throughout the growing season, and both dry matter content and sugar concentration are significantly increased during fruit ripening. Harmanto et al., [10] Singh et al. [11] and other studies have reached the same conclusion. Based on the complexity and real-time of irrigation process, Chen et al. [12] developed a water-saving irrigation management and decision support system software and made irrigation forecasts to determine the precise irrigation time and irrigation volume. However, there are still deficiencies in timeliness and dynamics. Due to the complexity of water-saving irrigation systems and statistical errors and lags, the accuracy and real-time of some data are reduced, so the system's decision accuracy is not high enough. Based on Internet of Things technology and wireless sensor technology, Li et al. [13] designed an intelligent water-saving irrigation system, combined with the growth information of different crops and different periods. The system regarded the variation of soil humidity content and the rate of deviation change as input to establish fuzzy control rules base. Finally, the rules base demonstrated the effectiveness of the fuzzy control strategy. However, the impact of crop environmental information on irrigation volume has not been considered, and there are certain difficulties in the design of fuzzy rules and membership functions for fuzzy control rule bases. In view of the problem of predicting effluent total phosphorus in the sewage treatment process, Qiao et al. [14] proposed a prediction method based on improved LM and SVD for online modeling of self-organizing fuzzy neural networks, which improved the detection accuracy and real-time performance. Wang et al. [15] used BP neural network to simulate the irrigation water demand and proposed a greenhouse cucumber irrigation model based on BP neural network. However, due to considering fewer parameters, the efficiency and accuracy of the prediction model needs to be improved. Chen et al. [16] proposed a short-term water temperature prediction method for pond culture based on GA-BPNN, which solved the problems of low accuracy and poor robustness of traditional water temperature prediction methods, but it did not consider adopting fuzzy theory to solve the multi-factor decision problems. 
Based on previous researches [8-16], this paper combined fuzzy theory with neural network to make decisions for water-saving irrigation with T-S fuzzy neural network based on genetic optimization for greenhouse tomatoes. This method overcomes the problem of low accuracy in fuzzy system, and it has better effect than the system which only uses the artificial neural network (ANN). Through real-time environmental data such as the temperature and humidity of air and soil, solar radiation in greenhouse by the Internet of Things, and combined with information on current tomatoes' growth and development stages, etc., the demand pattern and influencing factors of tomatoes under the condition of regulated deficit irrigation are analyzed. The T-S fuzzy neural network based on improved genetic algorithm (GA-TSFNN) is used to construct a water-saving irrigation decision-making model for greenhouse tomatoes, so that the soil is always maintained in the most appropriate humidity state for tomatoes growth, and accurate irrigation can be achieved through a scientific and reasonable water management system.

\section{The decision-making model of water-saving irrigation}

\subsection{Fuzzy Neural Network}

Fuzzy neural network(FNN) integrates artificial neural network(ANN) with the fuzzy theory or fuzzy weight coefficient, and it makes up for the defects and deficiencies of the two, through establishing a fuzzy neural network model to take advantages of them, so it has both self-learning ability of neural network and the ability of fuzzy logic to process uncertain information [17]. The theory and application of T-S fuzzy neural network are more researched, especially in the field of pattern recognition and control. The factors affecting the water management for greenhouse tomatoes have air temperature and humidity, soil temperature and humidity, solar radiation, ground evapotranspiration, and etc [18]. This is a typical multi-factor decision problem. Therefore, this paper chooses T-S fuzzy neural network to make decisions on the water-saving irrigation for greenhouse tomatoes.

The T-S fuzzy system has the self-learning function of automatically updating and modifying the membership function of the fuzzy subset using the "if-then" rule to define [19]. When the rule is expressed by $\mathrm{R}^{\mathrm{i}}$, the derivation formula is as follows:

$$
\begin{aligned}
& \mathrm{R}^{i}: \text { If } x_{1} \text { is } A_{1}^{i}, x_{2} \text { is } A_{2}^{i}, \cdots, x_{k} i s A_{k}^{i} \\
& \text { then } y_{i}=p_{0}^{i}+p_{1}^{i} x_{1}+\cdots+p_{k}^{i} x_{k}
\end{aligned}
$$

where $A_{j}^{i}$ is the fuzzy set of fuzzy system, $p_{j}^{i}(j=1,2, \cdots, k)$ is the fuzzy system parameter, $x_{1}, x_{2}, \cdots, x_{k}$ are the fuzzy input quantities, and $\mathrm{y}_{i}$ is the output result deduced from the fuzzy rules, and the inference rules indicate that the output is the linear combination of the input. 
Set the input variable $x=\left(x_{1}, x_{2}, \cdots, x_{k}\right)$ and calculate the degree of membership of each input variable based on the fuzzy membership function. The formula is as follows:

$$
\mu_{A_{j}^{i}}=\exp \left(-\left(x_{j}-c_{j}^{i}\right)^{2} / b_{j}^{i}\right), j=1,2, \cdots, k ; i=1,2, \cdots, n
$$

where $c_{j}^{i}$ and $b_{j}^{i}$ are the center and width of the membership function respectively, $k$ is the number of input parameters, and $n$ is the number of fuzzy subsets.

Use the membership function to perform fuzzification calculations on each input and then use the fuzzy continuous multiplication operator to calculate the weight $w^{i}$ as Eq. (3).

$$
w^{i}=\mu_{A_{j}^{1}}\left(x_{1}\right) * \mu_{A_{j}^{2}}\left(x_{2}\right) * \cdots \cdots * \mu_{A_{j}^{k}}\left(x_{k}\right), i=1,2, \cdots, n
$$

Calculate the output value of fuzzy reasoning $y_{i}$ based on the fuzzy weight as Eq. (4).

$$
y_{i}=\sum_{i=1}^{n} w^{i}\left(p_{0}^{i}+p_{1}^{i} x_{1}+\cdots+p_{k}^{i} x_{k}\right) / \sum_{i=1}^{n} w^{i}
$$

The T-S fuzzy neural network consists of five layers: input layer, fuzzy layer, fuzzy logic reasoning layer, summation layer and output layer [20]. The input vector $X_{i}$ is connected to the input layer, and the input vector has the same number of dimensions as the number of nodes. In the fuzzy layer, the membership function as Eq. (2) is used to fuzz the input values to obtain the fuzzy membership value $\mu$. The fuzzy inference layer is calculated by using the fuzzy continuous multiplication operator as Eq. (3). The summation layer and the output layer adopt Eq. (4) to calculate the output value [21].

\subsection{The Influence Factors of Irrigation Volume}

The growth environment of greenhouse tomatoes is very different from that of outdoor cultivation. The light conditions are weaker, the increasing temperature and humidity is significant, the wind speed is smaller, and the air humidity is higher. Therefore, the microclimate effect is significant. As a result, the crop evapotranspiration of greenhouse tomatoes has its particularity. According to the investigation and research [5], the crop evapotranspiration $\left(\mathrm{ET}_{\mathrm{e}}\right)$ is calculated using the reference crop evapotranspiration $\left(\mathrm{ET}_{0}\right)$ multiplied by the crop coefficient $\left(\mathrm{K}_{\mathrm{e}}\right)$. The formula is as Eq. (5).

$$
\mathrm{ET}_{\mathrm{e}}=\mathrm{K}_{\mathrm{e}} \cdot \mathrm{ET}_{0}
$$


The crop coefficient is a reflection of the physiological characteristics of the crop itself. It is related to crop types, farming conditions, soil fertility, crop leaf area, yield levels, and growth period [12]. Crop coefficient can be obtained in two ways. First, the user enters the crop coefficients for different crops at different growth stages. Second, the crop coefficient values are searched for by the single-average average method recommended by the Food and Agriculture Organization of the United Nations (FAO). Then the final $\mathrm{K}_{\mathrm{e}}$ value is corrected.

The reference crop evapotranspiration $\left(\mathrm{ET}_{0}\right)$ can be derived using the Penman-Monteith formula [5] obtained from the data acquired by the IoT sensors or local weather data as Eq. (6).

$$
\mathrm{ET}_{0}=\frac{0.408 \Delta \mathrm{R}_{n}+\gamma \frac{900}{T+273} U_{2}\left(e_{n}-e_{d}\right)}{\Delta+\gamma\left(1+0.34 U_{2}\right)}
$$

where $T$ is the daily average temperature $\left({ }^{\circ} \mathrm{C}\right), \mathrm{R}_{n}$ is the net radiation flux of the surface $\left(\mathrm{MJ} \cdot \mathrm{m}^{-2} \cdot \mathrm{d}^{-1}\right), \mathrm{e}_{n}$ 与 $e_{d}$ are the value of saturated vapor pressure and the actual water vapor pressure $(\mathrm{kPa})$ respectively, $U_{2}$ is the wind speed at the height of $2 \mathrm{~m}\left(\mathrm{~m} \cdot \mathrm{s}^{-1}\right), \Delta$ is the curve slope of the vapor pressure and the temperature in the saturated state $\left(\mathrm{kPa} \cdot \mathrm{C}^{-1}\right)$, and $\gamma$ is the dry wet table constant $\left(\mathrm{kPa} \cdot \mathrm{C}^{-1}\right)$. The greenhouse planting environment is a no-wind environment, and it is considered that $U_{2}=0$, thus the formula of $E T_{e}$ is as follows:

$$
E T_{\mathrm{e}}=K_{e} \frac{0.408 \Delta R_{n}}{\Delta+\gamma}
$$

\subsection{The Irrigation Decision Model for GA-TSFNN}

Fuzzy neural network algorithm combines with the advantages of fuzzy systems and neural networks which has the advantages of small dependence, strong self-learning ability, strong robustness, and etc, therefore it can better solve the typical multi-factor decision problems of water-saving irrigation for greenhouse tomatoes [22]. The block diagram of fuzzy neural network algorithm is shown in Fig. 1. 


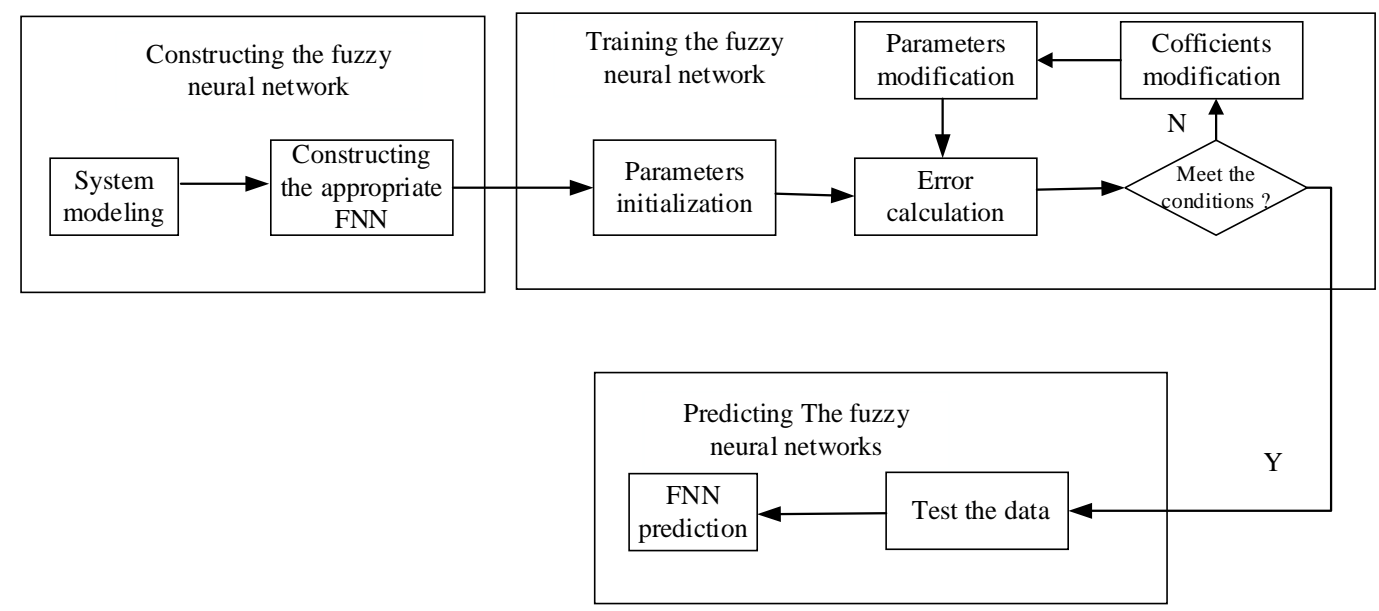

Fig. 1. The block diagram of fuzzy neural network algorithm

Based on the recommendations of relevant researchers and the study of relevant literatures, in view of the irrigation water data of greenhouse tomatoes and the analysis of the factors that influence the degree, we choose six input values as the index of evaluation and forecasting model of index system which contains the growth period, inside solar radiation, the soil humidity in $20 \mathrm{~cm}$ depth currently, soil temperature in $10 \mathrm{~cm}$ depth currently, inside air humidity and inside air temperature. The output value is irrigation volume [23], therefore it can realize the comprehensiveness of water saving irrigation index selection and at the same time reduce the complexity of the fuzzy neural network.

Genetic algorithm has a wide range of applicability and can handle arbitrarily complex objective functions and constraints. Since the genetic algorithm uses probability search instead of path search, it is a global search in probability. Regardless of whether the problem solved is convex, theoretically, the global optimal solution can be obtained and the local minimum point can be avoided. In addition to the selection, crossover, and mutation operators of genetic algorithms [24], this paper also introduced the constraint operator and update operator in the krill herd algorithm to simplify the fuzzy rules and improve the local search ability. Krill herd (KH) algorithm is a new kind of swarm intelligence approach for optimizing nonlinear functions in continuous space [25]. This way improves the convergence speed of genetic algorithm, reduces the complexity and guarantees the timely decision of the algorithm, which ensures the rationality of randomly generated fuzzy rules [26]. Firstly, we use genetic algorithm to search globally, optimize the initial weight of fuzzy neural network including connection weight $\omega$, membership function center $c_{j}^{i}$ and width $b_{j}^{i}$, etc., locate a good search space, and use T-S fuzzy neural network to search for optimal values in a small space $[27,28]$. The flowchart of GA-TSFNN is shown in Fig. 2. 


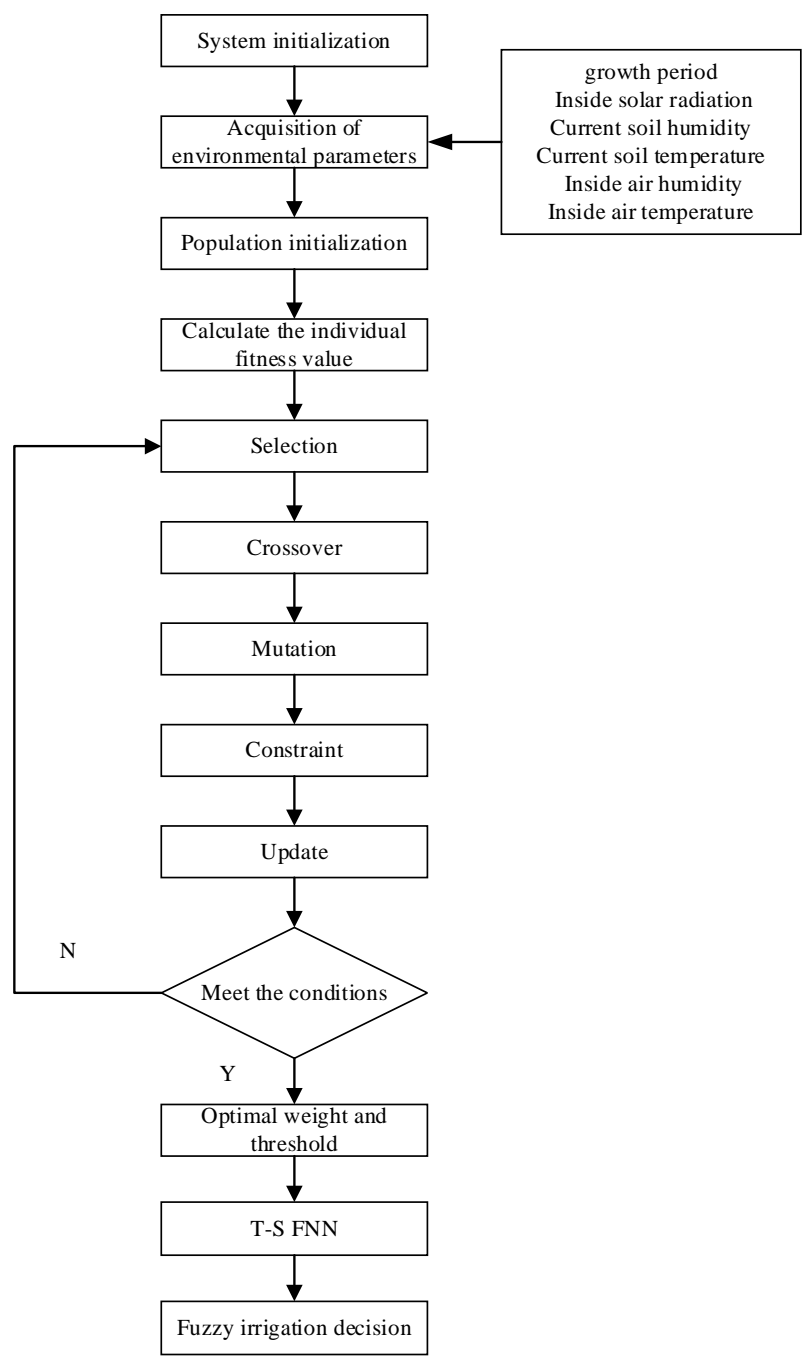

Fig. 2. The flowchart of GA-TSFNN

The specific steps of decision-making model of GA-TSFNN [29] are as follows:

(1) The collected greenhouse environmental factors such as growth period, inside solar radiation, soil temperature in $10 \mathrm{~cm}$ depth currently, soil humidity in $20 \mathrm{~cm}$ depth currently, inside air temperature and air humidity and other environmental factors are taken as the original data set.

(2) Using the normalization method to preprocess the data, the accuracy of the model is verified using 5 -fold cross validation.

(3) Initialize the population

A population is randomly generated. Each individual represents the initial weight of a neural network. Each gene is a connection weight. Floating-point coding is used to encode the weights. 
(4) Fitness function

The fitness function value $f$ of each individual is calculated by using the output error value $T$, and the individual of the greatest fitness function enters the subpopulation.

$$
f=\frac{1}{1+T}
$$

(5) Selection operator

The roulette method is used to select the operator. Assuming that $f_{i}$ is the adaptive value of the $i$-th individual, the probability of being selected is calculated as follows:

$$
p_{i}=\frac{f_{i}}{\sum_{i=1}^{m} f_{i}}
$$

where $m$ is the population size.

(6) Crossover operator

The crossover operator selects the arithmetic crossover which combines linear combinations of two individuals to get two new individuals. Supposing that the two individuals $X_{i}(k), X_{i+1}(k)$ are crossed with crossover probability $p_{c}$, the two new individuals are generated after the crossover are:

$$
\left\{\begin{array}{l}
X_{i}(k+1)=\alpha X_{i}(k)+\beta X_{i+1}(k) \\
X_{i+1}(k+1)=\alpha X_{i+1}(k)+\beta X_{i}(k)
\end{array}\right.
$$

where $X_{i}(k), X_{i+1}(k)$ represent the $k$ th genes of the $i$-th and $i+1$ th individuals respectively, $\alpha$ and $\beta$ are the random numbers between 0 and 1 respectively.

(7) Mutation operator

Select the homogenous mutation operator. For each gene value, replace the gene value field corresponding to the mutation rate $p_{m}$ by a random number.

$$
X_{i}=X_{i}(p)+r \times q+X_{i}(n-p-1)
$$

where $q$ is the threshold width corresponding to $p+1$ th gene value.

(8) Constraint operator

In order to ensure the rationality of the genetic algorithm to generate fuzzy rules, the constraint operator in the Krill herd algorithm [30] is introduced to obtain effective fuzzy rules. The constraint operator guarantees that the solution produced by each individual's behavior is legal. When the behavior of selection, crossover, and mutation is performed, a new feasible solution is generated according to the problem constraint conditions to ensure the rationality of each individual's structure and parameters [7]. 
1. If the threshold width $b_{j}^{i}$ of the Gaussian membership function is 0 , the rule is deleted.

2. If the connection weights of all elements in a rule are smaller than 0.001 , the sub-model of this rule is considered useless and is removed directly.

3. Sort the centers $c_{j}^{i}$ of Gaussian membership functions in ascending order. If the distance between adjacent centers $d c_{j}^{i}=\left|c_{j}^{i}-c_{j}^{i+1}\right|$ is too close, for example, $d c_{j}^{i} \leq \varepsilon, \varepsilon$ is the approximation of the function, the width corresponding to the center $c_{j}^{i}$ of membership function will be set to zero. The number of fuzzy rules is decreased.

(9) Update operator

The update operator records the fitness function value of the current individual. After each individual performs the selection, crossover, and mutation operations, the fitness function value is calculated, and the self-adaptation value is compared with the fitness value in the update operator, and the optimal individual is assigned to the update operator [31].

(10) Determine whether the conditions are met

Determine whether to reach the maximum number of iterations or meet the accuracy requirements. If yes, output the optimal solution; otherwise, return to step (2). After the genetics are completed, the optimal individuals obtained from the genetic algorithm are taken as the initial weights and thresholds of the neural network. Through the given sample data, the neural network is trained according to the T-SFNN and the optimal solution is obtained.

\subsection{The Evaluation Indexes of Models}

The relevant agricultural experts have researched on precision irrigation volume for greenhouse tomatoes [32,33], so this paper uses the actual irrigation volume as the standard. The performance of the algorithms is evaluated by comparing the error between the actual value and predicted value. In order to evaluate the performance of the water-saving irrigation decision-making model for greenhouse tomatoes comprehensively and accurately, a 5-fold cross validation was used to evaluate the prediction effect. the paper established four kinds of neural network model and they use three characteristic indexes to compare including the mean absolute percentage error (MAPE), root mean square error (RMSE) and mean absolute error (MAE) [34,35]. The expressions of each evaluation index are as follows:

$$
\text { MAPE }=\frac{1}{n} \sum_{i=1}^{n} \frac{\left|y_{i}-\hat{y}_{i}\right|}{\left|y_{i}\right|}
$$




$$
\begin{aligned}
& \text { RMSE }=\sqrt{\frac{1}{n} \sum_{i=1}^{n}\left(y_{i}-\hat{y}_{i}\right)^{2}} \\
& M A E=\frac{1}{n} \sum_{i=1}^{n}\left|y_{i}-\hat{y}_{i}\right|
\end{aligned}
$$

where $y_{i}$ and $\hat{y}_{i}$ represent the actual value and the predicted value respectively, and $n$ represents the number of test samples.

\section{Simulation Experiment}

All the codes in this experiment are written on the MATLAB R2014a software platform, and the PC parameters for compilation and operation are: Intel(R) Core(TM)i5-4460 CPU @3.20GHz, RAM 8.00GB, 64-bit Windows10 operating system.

\subsection{Data Collection and Processing}

In this paper, the experimental data is collected from the tomato sunlight greenhouse of Xiaotangshan National Precision Agriculture Research and Demonstration Base in Changping District of Beijing $\left(40^{\circ} 10^{\prime} 43^{\prime \prime} \mathrm{N}, 116^{\circ} 26^{\prime} 39^{\prime \prime} \mathrm{W}\right)$ by installing of various sensors, such as soil temperature and humidity sensor, air temperature and humidity sensor, solar radiation sensor, and etc. The test greenhouse is $29 \mathrm{~m}$ in length and $8 \mathrm{~m}$ in width, and the experiment area is $5 \mathrm{~m}$ in length and $1.4 \mathrm{~m}$ in width. Two rows of tomatoes are planted in each zone. The cultivation method is to cover the plants with a row spacing of $60 \mathrm{~cm}$ and a spacing of $35 \mathrm{~cm}$. The $60 \mathrm{~cm}$ high PVC plates are used for isolation between the communities. The test tomato variety is xianke 8. The collection time is from March 21 to July 18, 2016. The growth period of tomatoes is divided into germination period (March 21 to March 27), seedling period (March 28 - April 27), flowering and fruit-setting period (April 28 - June 2nd) and mature picking period (June 3 - July 18).

Based on the recommendations of relevant researchers and the study of relevant literatures, in view of the analysis of the irrigation data and the influence degree of the relevant factors on greenhouse tomatoes, we choose six input values as the index of evaluation and forecasting model of index system which contains the growth period, inside solar radiation, the soil humidity in $20 \mathrm{~cm}$ depth currently, soil temperature in $10 \mathrm{~cm}$ depth currently, inside air humidity and inside air temperature. The output value is irrigation volume. The daily average value of inside solar radiation during the experiment is shown in Fig. 3 . When the weather is cloudy, the daily average inside solar radiation is low. The daily average relative humidity of soil and air during the experiment is presented in Fig. 4. the daily average value 
of soil and air temperature is shown in Fig. 5. The calculated results of daily $\mathrm{ET}_{\mathrm{e}}$ of single tomato are shown in Fig. 6 which are calculated by the local climatic data and formula (7). The water requirement of the tomato plants is small at the germination stage, and the growth of the plants during the germination stage and the seedling stage is still relatively slow. The branches and leaves are not luxuriant enough, and their water requirement strength is still relatively small. In the fruit-setting and full fruit period, due to the dense foliage and the transfer of tomato from plant growth to reproductive growth, the water requirement increases [11]. The evapotranspiration of tomatoes increased at first and then decreased, and the maximum evapotranspiration of the tomatoes plants occurred in fruit setting period (highest on May 21). With the growth of tomatoes, the temperature and humidity of soil and air in the greenhouse rises fluctuatingly. Due to the instability of the spring climate, the temperature fluctuates greatly during the seedling period and the humidity is low. After 40 days of tomato colonization, the temperature and humidity increased significantly. After 100 days of tomato colonization, both temperature and humidity fluctuate greatly. This is related to factors such as the opening of the greenhouse vents.

In fuzzy neural network learning, because the activation function of neurons is bounded function, the input and output vectors need to be normalized processing before the training and prediction. The formatting formula is as follows:

$$
\mathrm{y}=\left(x-x_{\min }\right) /\left(x_{\max }-x_{\min }\right)
$$

where $y$ is the result of the formatting process, $x$ is the original data, $x_{\min }$ is the minimum value of the data set, and $x_{\max }$ is the maximum value of the data set.

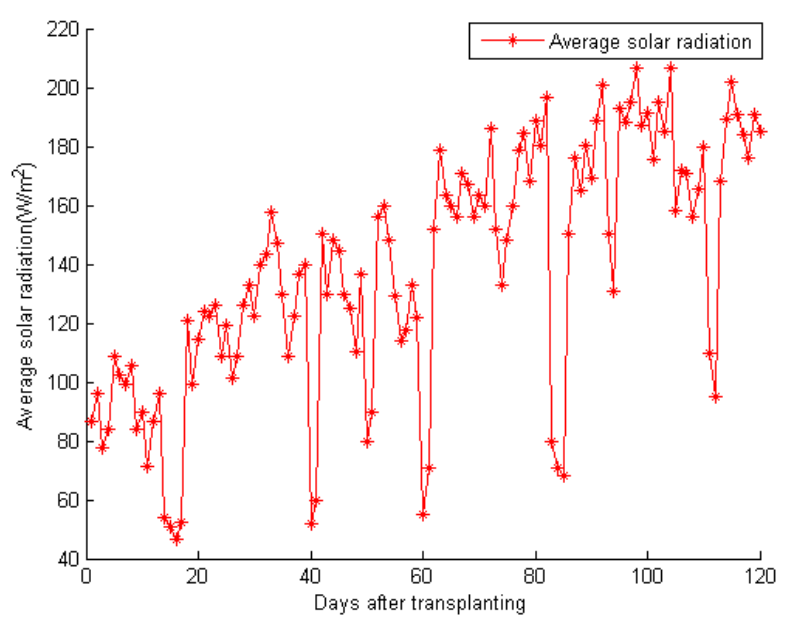

Fig. 3. The daily average inside solar radiation during the experiment 


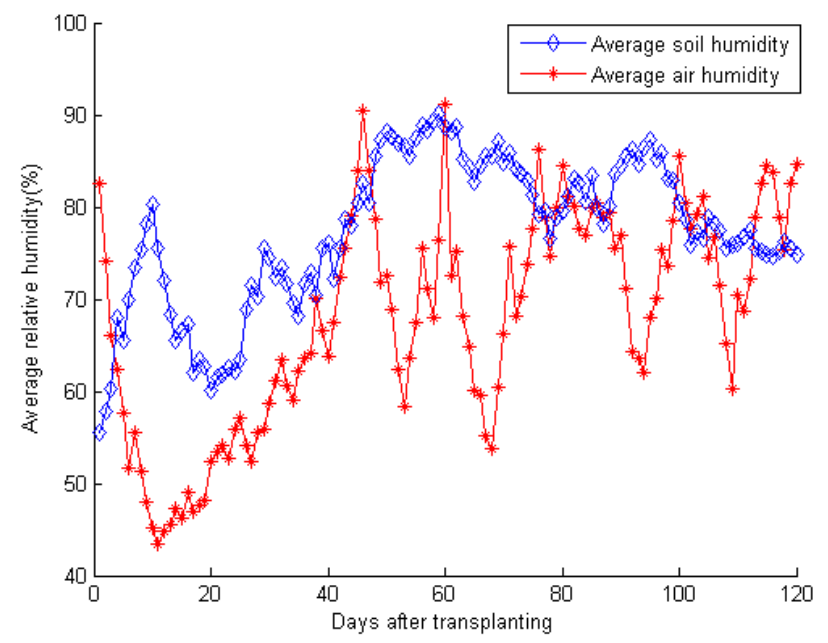

Fig. 4. The daily average relative humidity of soil and air during the experiment

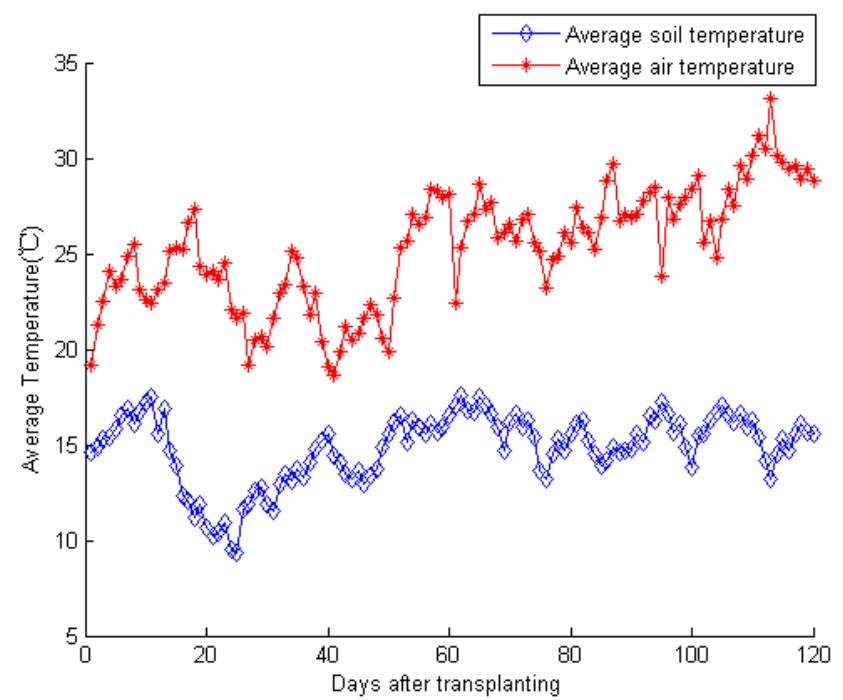

Fig. 5. The daily average temperature of soil and air during the experiment 


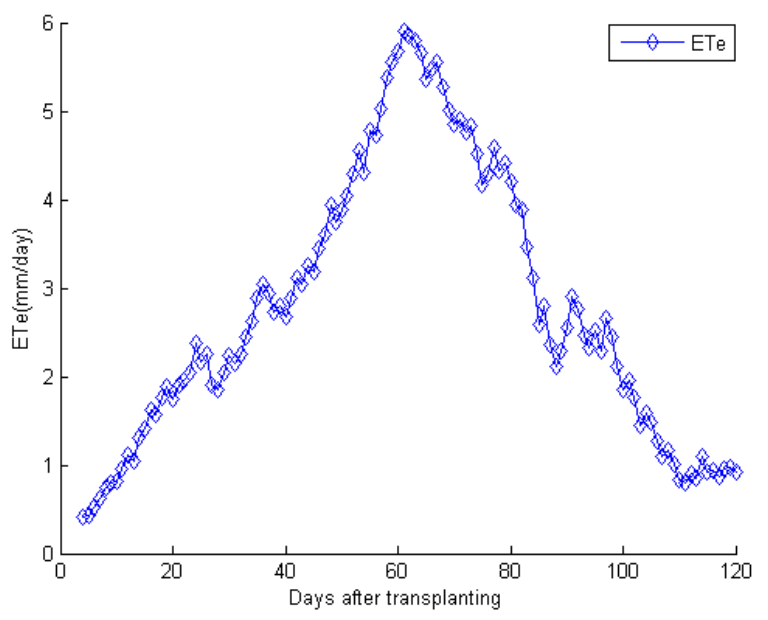

Fig. 6. The daily $\mathrm{ET}_{\mathrm{e}}$ of single tomato during the experiment

\subsection{Parameter Setting of The Algorithm}

500 sets of sample data were collected and the accuracy of the trained neural network model was verified by a 5 -fold cross validation method. The sample data set is randomly divided into five parts, of which four are used as a training data set and one is used as a test data set. The process is repeated until all five data sets have one time as a test data set. Finally, the average of five prediction results is used as an estimate of the accuracy of the algorithm. The genetic algorithm uses the random problem hypothesis set to evaluate the individual according to the fitness function. The improved genetic algorithm simulates the phenomenon of selection, crossover, and mutation in the genetic process, and combines the constraint operator and the update operator to optimize the individuals. The genetic algorithm optimizes the initial weights and thresholds of the T-S fuzzy network, and then uses the T-S fuzzy neural network prediction model to perform local optimization.

In the evolution process of the genetic algorithm, the volume of population is 20, the maximum evolutionary generation is 40 , the crossover probability is 0.5 , and the mutation probability is 0.2 . The parameters of the T-S fuzzy neural network are as follows: the number of input layer nodes is 6 , the number of logic reasoning layer nodes is 12 , and the number of output layer nodes is 1 . MAPE, RMSE and MAE are selected as the evaluation index of the model performance. 


\subsection{Simulation Results and Analysis}

Based on the data it trained the established GA-TSFNN, TSFNN [14], BPNN [15] and GA-BPNN [16]. According to the differential of the actual output value and the desired output value, it adjusted the positive and negative weights of the corresponding input variables. If the actual output value is greater than the desired output, the weight of all connections with positive input is reduced and the weight of all connections with negative output is increased. On the contrary, if the actual output value is smaller than the desired output, the weight of all connections with positive input is increased and the values of all connections with negative output is reduced.

Fig. 7 shows the training results of the fitness value of the four neural network algorithms. The initial fitness value of GA-TSFNN algorithm is approximately 0.25 , and then the fitness value rises rapidly. When the number of iterations is about 15 , it tends to be flat, reaching a stable value of about 0.7 . The initial fitness value of the TSFNN algorithm is about 0.24 , which then rises in the tortuosity, reaches a peak value of 0.58 approximately 25 iterations, then gradually decreases, and tends to stabilize at the 34 iterations, reaching 0.48 . The initial value of fitness value of BPNN algorithm is about 0.23 , and then it rises in the tortuosity. When the number of iterations is 20 , the fitness value reaches a peak value of 0.52 , and then tends to stabilize at the 31 iterations, reaching 0.43 . The initial value of fitness value of GA-BPNN algorithm is about 0.24 , and then it rises in the tortuosity. When the number of iterations is 18 , the fitness value reaches a peak value of 0.6 , and then it continues to fluctuate and fluctuate in twists and turns.

The fitness values of the four algorithms are all around 0.25 at the beginning. Since the number of iterations for taking the fitness peak is less than 25 , it is reasonable to take 40 iterations. The TSFNN algorithm has premature convergence because there is no adaptive change of crossover operator and mutation operator. Since the BPNN algorithm does not introduce an optimization algorithm, it is easy to achieve local convergence and low fitness. Due to not introducing the genetic diversity function of a single adaptive mutation genetic strategy, the fitness value of GA-BPNN algorithm constantly fluctuates, and the population evolution process has a retrogression, therefore it is unable to achieve the optimal solution. The fitness value of GA-TSFNN algorithm converges quickly, and the fitness value is improved from below 0.6 to 0.7 . Therefore, the training result is better. 


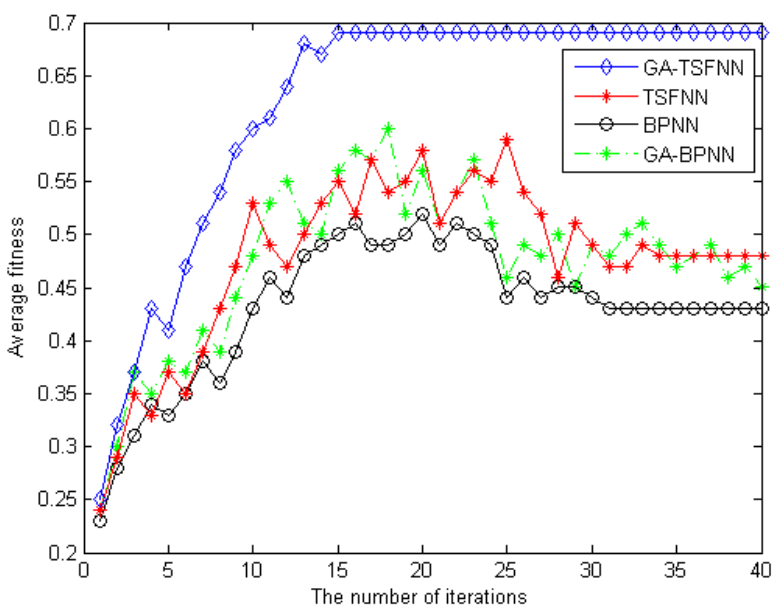

Fig. 7. The fitness curve of the four algorithms

According to the sample data, the paper uses 5-fold cross validation to verify the accuracy of the algorithms. the irrigation volume of the four algorithms after training is predicted. The one experiment results of comparisons between the actual values and predictive values of the GA-TSFNN, TSFNN, BPNN and GA-BPNN algorithms are shown in Fig. 8, Fig. 9, Fig. 10 and Fig. 11, respectively. The error comparisons of the irrigation volume among the four algorithms is shown in Fig. 12. It can be seen from the Fig. 12 that the error of GA-TSFNN algorithm is about 0.1 , the error of TSFNN algorithm is approximately 0.25 , the error of BPNN algorithm is approximately 0.4, and the error of GA-BPNN algorithm is approximately 0.3. Therefore, the GA-TSFNN algorithm proposed in this paper is smaller error than TSFNN, BPNN and GA-BPNN algorithm within the allowable range and the prediction effect is better.

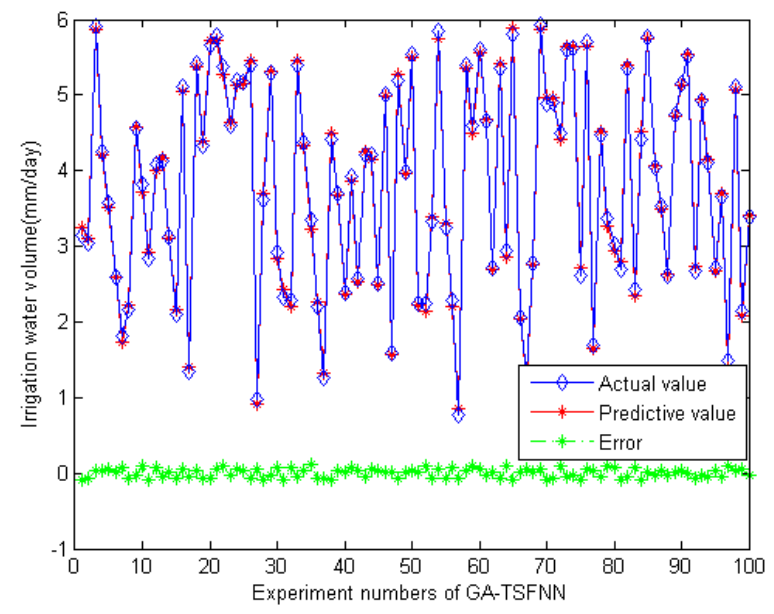

Fig. 8. The comparisons of the irrigation volume between the actual value and predictive value of GA-TSFNN 


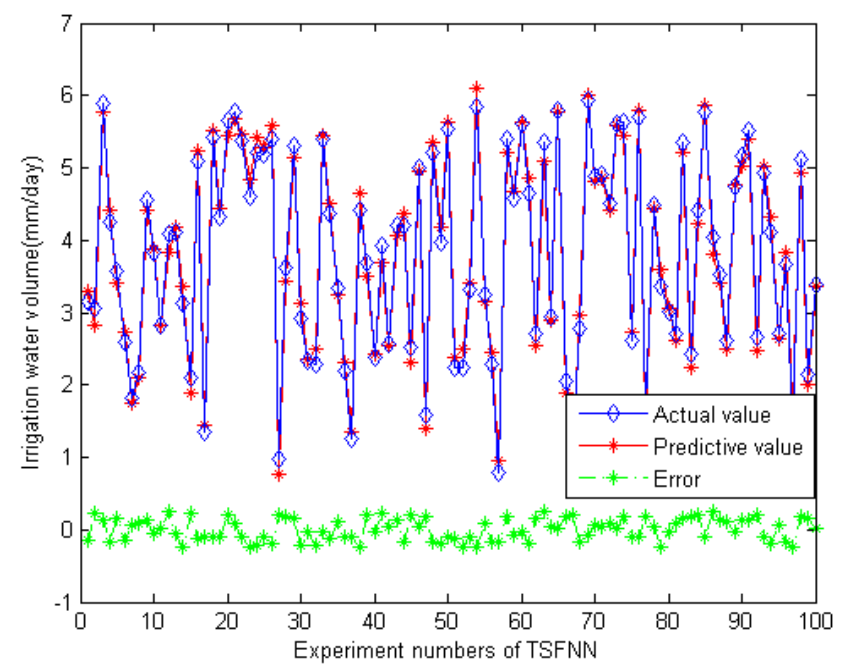

Fig. 9. The comparisons of the irrigation volume between the actual value and predictive value of TSFNN

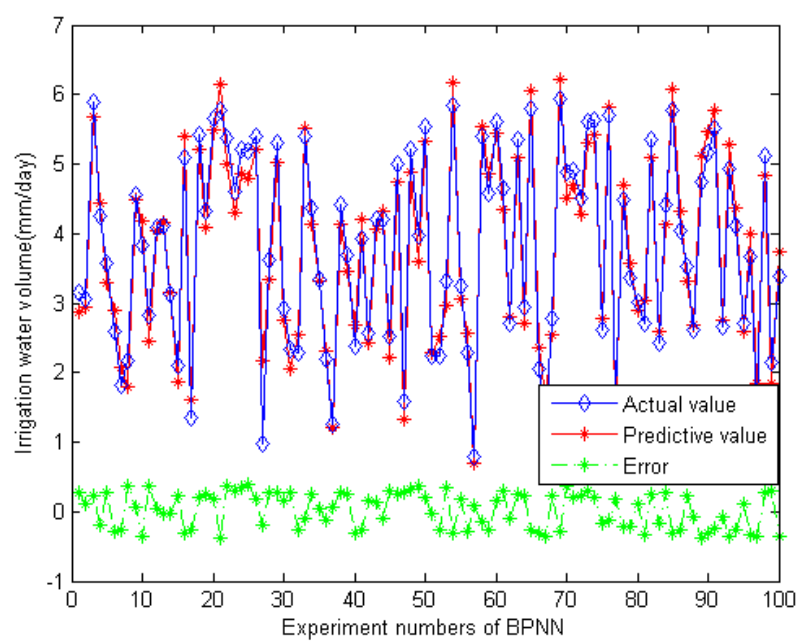

Fig. 10. The comparisons of the irrigation volume between the actual value and predictive value of BPNN 


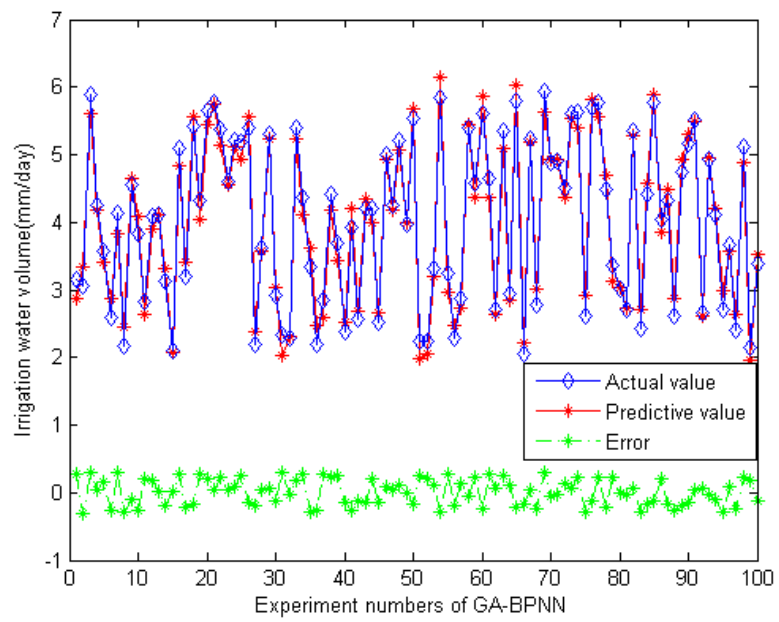

Fig. 11. The comparisons of the irrigation volume between the actual value and predictive value of GA-BPNN

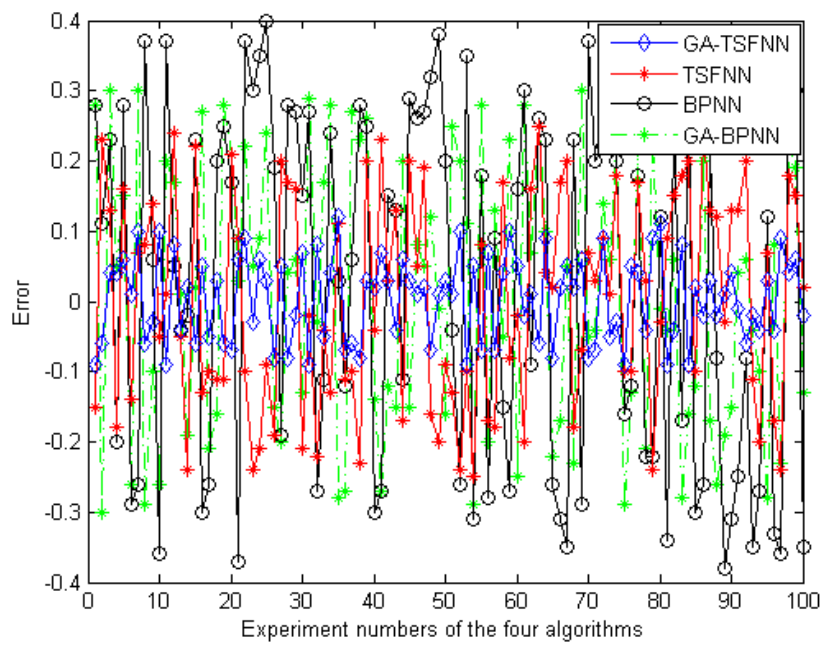

Fig. 12. The error comparisons of the irrigation volume among the four algorithms

The average comparisons of five tests for evaluation indexes among the four algorithms are shown in Fig. 13. It can be seen that the values of MAPE, RRMSE and MAE of GA-TSFNN are 0.0358, 0.1086 and 0.0803, respectively, and the values of MAPE, RRMSE and MAE of TSFNN are 0.0651, 0.1252 and 0.1033, respectively. The values of MAPE, RRMSE and MAE of BPNN are 0.0583, 0.1426 and 0.1297, respectively. The values of MAPE, RRMSE and MAE of GA-BPNN are 0.0469, 0.1397 and 0.1135, respectively. Compared with the TSFNN, the values of GA-TSFNN increased $45.0 \%, 13.3 \%$ and $22.3 \%$ respectively in MAPE, RMSE and MAE. Compared with BPNN, the values of GA-TSFNN improved 38.6\%, 23.8\% and 38.1\% respectively in MAPE, RMSE and MAE. Compared 
with GA-BPNN, the values of GA-TSFNN improved 23.7\%, 22.3\% and 29.3\% respectively in MAPE, RMSE and MAE. Thus, compared with TSFNN, BPNN and GA-BPNN models, the GA-TSFNN has the smallest values of MAPE, RMSE and MAE, and the fitting effect is better than TSFNN, BPNN and GA-BPNN models. The GA-TSFNN model improved on forecasting accuracy significantly and it can predict well real-time irrigation volume for greenhouse tomatoes.

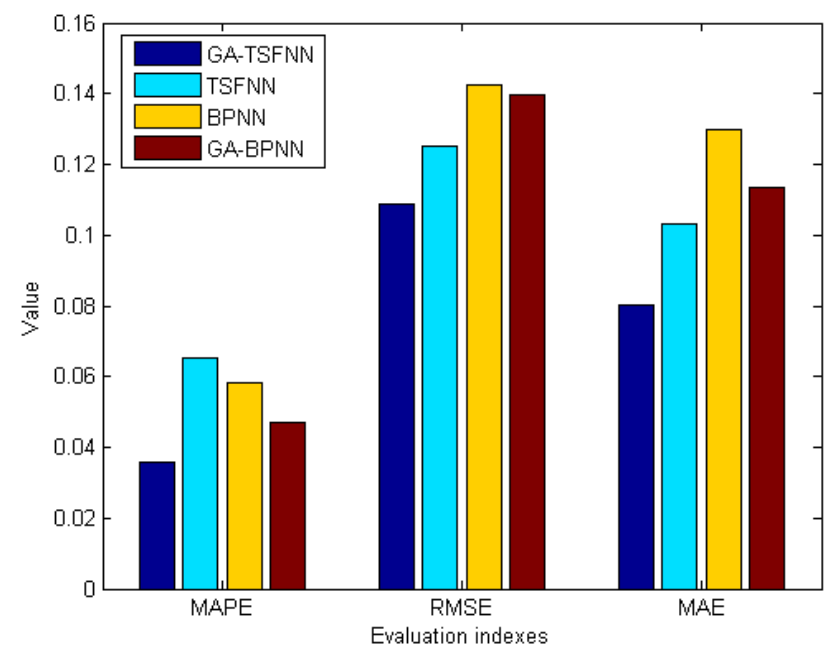

Fig. 13. The average comparisons of five tests for the evaluation indexes among the four algorithms

\section{Conclusion}

In this paper, a water-saving irrigation decision-making model for greenhouse tomatoes based on genetic optimization T-S fuzzy neural network named GA-TSFNN is proposed. We have improved the GA algorithm by combining the constraint operator and update operator originated from $\mathrm{KH}$ algorithm, and we also have optimized the initial weights and thresholds of the TS fuzzy neural network using the improved genetic algorithm. In addition, on the basis of the real data set, we have evaluated the accuracy of the GA-TSFNN by simulating and predicting the irrigation volume of greenhouse tomatoes. The results show that compared with the TSFNN, BPNN and GA-BPNN algorithms, GA-TSFNN can be used to predict the water-saving irrigation volume of greenhouse tomatoes, which can obtain better forecasting accuracy and guide irrigation decisions for greenhouse tomatoes. This algorithm has advantages of self-learning ability and strong knowledge expression ability which can be modified constantly during neural network training and testing data. It improves the global search ability, convergence accuracy and speed of the algorithm to some extent.

For future studies, we will improve current research from following several aspects. First of all, the influence of the GA-TSFNN parameters on convergence and performance can be carefully analyzed and investigated in order to achieve the GA-TSFNN optimization. 
Secondly, constraint operators of the GA-TSFNN should be further refined. Finally, other optimization algorithms can be considered to optimize the fuzzy neural network such as an improved krill herd algorithm [7,25,26,30], cuckoo search algorithm [36] and firefly algorithm [37].

\section{References}

[1] Zhang, Z., Gao, L., Ren, H., Chen, Q., Wang, Q., Sui, X., "Research Progress on Modern Water-saving Technology for Protected Vegetable Crops[J],” CHINA VEGETABLES, vol. 18, pp. 21-25, 2012. Article (CrossRef Link).

[2] Wang, F., Du, T., Qiu, R., et al., "Effects of deficit irrigation on yield and water use efficiency of tomato in solar greenhouse[J]," Transactions of the CSAE, vol. 26, no. 9, pp. 46-52, 2010. Article (CrossRef Link).

[3] Liu, M., Zhang, S., Liu, X., "Effects of different deficit irrigation periods on yield and fruit quality of tomato[J],"'Transactions of the CSAE, vol. 21, no. S12, pp. 92-95, 2005. Article (CrossRef Link).

[4] Ji, R., Qi, L., Huo, Z., "Design of Fuzzy Control Algorithm for Precious Irrigation System in Greenhouse[J],” IFIP International Federation for Information Processing, vol. 370, pp. 278-283, 2012. Article (CrossRef Link).

[5] Zhang, W., Dang. J., Zhao. L, "Comparison of $\mathrm{ET}_{0}$ Estimated by Penman-Monteith and Modified Penman Methods[J],” Water Saving Irrigation, no. 12, pp. 54-59, 2010.

Article (CrossRef Link).

[6] Giusti, E., Marsili-Libelli, S., "A Fuzzy Decision Support System for irrigation and water conservation in agriculture[J],” ENVIRON MODELL SOFTW, vol. 63, pp.73-86, 2015.

Article (CrossRef Link).

[7] Wang, G., Gandomi, A.H., Alavi, A.H., Deb, S., "A hybrid method based on krill herd and quantum-behaved particle swarm optimization[J],” Neural Computing and Applications, vol. 27, no.4, pp. 989-1006, 2016. Article (CrossRef Link).

[8] Liu, H., Sun, J., Wang, C., Liu, Z., "Analysis of Water Requirement Characteristics and Influencing Factors of Greenhouse[J],” Water Saving Irrigation, no. 4, pp. 11-14, 2011.

Article (CrossRef Link).

[9] Kumar, P.S., Singh, Y., Nangare, D.D., Bhagat, K., Kumar, M., Taware, P.B., Kumari, A., Minhas, P.S., "Influence of growth stage specific water stress on the yield, physico-chemical quality and functional characteristics of tomato grown in shallow basaltic soils[J]," SCI HORTIC-AMSTERDAM, vol. 197, pp. 261-271, 2015. Article (CrossRef Link).

[10] Harmanto, Salokhe, V.M., Babel, M.S., Tantau, H.J., "Water requirement of drip irrigated tomatoes grown in greenhouse in tropical environment[J]," Agricultural Water Management, vol. 71, no. 3, pp. 225-242, 2005. Article (CrossRef Link). 
[11] Singh, K.G., Kumar, S., Nangare, D.D., "Effect of blending fresh-saline water and discharge rate of drip on plant yield, water use efficiency (WUE) and quality of tomato in semi arid environment[J]," African Journal of Agricultural Research, vol. 8, no. 27, pp. 3639-3645, 2013. Article (CrossRef Link).

[12] Chen, Z., Song, N., Wang, J., "Water-saving irrigation management and decision support system[J],” Transactions of the CSAE, vol. 25, no. 13, pp. 1-6, 2009. Article (CrossRef Link).

[13] Li, C., Gao, L., Li, Y., "An Intelligent Irrigation System Based on Internet of things technology and Fuzzy Control[J],” Water Saving Irrigation, no. 12, pp. 83-86, 2013.

Article (CrossRef Link).

[14] Qiao, J., Zhou, H., "Prediction of effluent total phosphorus based on self-organizing fuzzy neural network[J],” Control Theory \& Applications, vol. 34, no. 2, pp. 224-232, 2017.

Article (CrossRef Link).

[15] Wang, H., Zhang, M., et, al., "Greenhouse Cucumber Irrigation Prediction Model Based on BP Neural Network[J],” Jiangsu Agricultural Sciences, vol. 41, no. 11, pp.407-409, 2013.

Article (CrossRef Link).

[16] Chen, Y., Cheng, Q., Cheng, Y., Yu, H., Zhang, C., "Short-term Prediction System of Water Temperature in Pond Aquaculture Based on GA-BP Neural Network[J]," Transactions of the Chinese Society for Agricultural Machinery, vol. 48, no. 8, pp. 172-178, 2017.

Article (CrossRef Link).

[17] Gong, X., Liu, H., Liu, D., Wang, W., Sun, J., "Fuzzy comprehensive evaluation on regulated deficit irrigation scheduling of tomato drip irrigated in solar greenhouse[J]," Transactions of the Chinese Society of Agricultural Engineering (Transactions of the CSAE), vol. 33, no. 14, pp. 144-151, 2017. Article (CrossRef Link).

[18] Shen, G., Li, J., Hu, X., Chen, X., "Evaluation and Prediction Model of Agricultural Drought Based on T-S Fuzzy Neural Network[J]," Natural Science Journal of Harbin Normal University, vol. 32, no. 6, pp. 34-37, 2016. Article (CrossRef Link).

[19] Tseng, K., Tsai, J.S., Lu, C., "Design of Delay-Dependent Exponential Estimator for T-S Fuzzy Neural Networks with Mixed Time-Varying Interval Delays Using Hybrid Taguchi-Genetic Algorithm[J],” NEURAL PROCESS LETT, vol. 36, no. 1, pp. 49-67, 2012.

Article (CrossRef Link).

[20] Malek, H., Ebadzadeh, M.M., Rahmati, M., "Three new fuzzy neural networks learning algorithms based on clustering, training error and genetic algorithm[J]", APPLIED INTELLIGENCE, vol. 37, no. 2, pp. 280-289, 2012. Article (CrossRef Link).

[21] Safavi, H.R., Rezaei, F., "Conjunctive use of surface and ground water using fuzzy neural network and genetic algorithm[J]”, IJST, Transactions of Civil Engineering, vol. 39, no. C2, pp. 365-377, 2015. Article (CrossRef Link).

[22] Bai, J., "The application of neural network based on t-s model in the selection of water-saving irrigation technology[J]," Technical Supervision in Water Resources, vol. 24, no. 1, pp. 40-42, 2016. Article (CrossRef Link). 
[23] Huang, B., Gui, F., Zhang, X., "Study of the suitable water-saving technique model based on fuzzy neural network for Wannian County[J],” Procedia Engineering, vol. 15, pp. 4362-4366, 2011. Article (CrossRef Link).

[24] Jin, H., Song, X., Wang, M., Niu Y., Li, K., “A Fast Anti-jamming Decision Method Based on the Rule-Reduced Genetic Algorithm[J],” KSII T INTERNET INF, vol. 10, no. 9, pp. 4549-4567, 2016. Article (CrossRef Link).

[25] Wang, G., Gandomi, A.H., Yang, X., Alavi, A.H., “A new hybrid method based on krill herd and cuckoo search for global optimisation tasks[J],” Int J of Bio-Inspired Computation, vol. 8, no. 5, pp. 286-299, 2016. Article (CrossRef Link).

[26] Wang, G., Gandomi, A.H., Alavi, A.H., Deb, S., “A multi-stage krill herd algorithm for global numerical optimization[J],” INT J ARTIF INTELL T, vol. 25, no. 2, pp. 1-17, 2016.

Article (CrossRef Link).

[27] Sharifian, A., Ghadi, M.J., Ghavidel, S., Li, L., Zhang, J., “A new method based on Type-2 fuzzy neural network for accurate wind power forecasting under uncertain data[J],” RENEW ENERG, vol. 120, pp. 220-230, 2018. Article (CrossRef Link).

[28] Zhang, R., Tao, J., “A Nonlinear Fuzzy Neural Network Modeling Approach Using an Improved Genetic Algorithm[J],” IEEE T IND ELECTRON, vol. 65, no. 7, pp. 5882-5892, 2018. Article (CrossRef Link).

[29] Han, M., Sun, Y., Fan, Y., “An improved fuzzy neural network based on T-S model[J],” Expert Systems with Applications, vol. 34, no. 4, pp. 2905-2920, 2008. Article (CrossRef Link).

[30] Wang, G., Gandomi, A.H., Alavi, A.H., Hao, G., "Hybrid krill herd algorithm with differential evolution for global numerical optimization[J],” Neural Computing and Applications, vol. 25, no. 2, pp. 297-308, 2014. Article (CrossRef Link).

[31] Guo, L., Wang, G., Gandomi, A.H., Alavi, A.H., Duan, H., “A new improved krill herd algorithm for global numerical optimization[J],” NEUROCOMPUTING, vol. 138, pp. 392-402, 2014. Article (CrossRef Link).

[32] Young, C., Liu, W., Chung, C., "Genetic algorithm and fuzzy neural networks combined with the hydrological modeling system for forecasting watershed runoff discharge[J],” Neural Computing and Applications, vol. 26, no. 7, pp. 1631-1643, 2015. Article (CrossRef Link).

[33] Li, Y., Xue, X., Zhao, Q., et al., “Automatic measurement of greenhouse tomato evapotranspiration based on negative pressure irrigation system[J]," Transactions of the Chinese Society of Agricultural Engineering (Transactions of the CSAE), vol. 33, no. 10, pp. 137-144, 2017. Article (CrossRef Link).

[34] Li, Y., Xu, F., Xue, X., et al., "Effects of Negative Pressure Fertigation on Tomato Water Use Efficiency in Solar Greenhouse[J],” Water Saving Irrigation, no. 12, pp. 42-45, 2016.

Article (CrossRef Link).

[35] Guan, H., Dai, Z., Zhao, A., He, J., “A novel stock forecasting model based on High-order-fuzzy-fluctuation Trends and Back Propagation Neural Network[J],” PLOS ONE, vol. 13, no. 2, pp. 1-15, 2018. Article (CrossRef Link). 
[36] Wang, G., Gandomi, A.H., Zhao, X., Chu, H.C.E., "Hybridizing harmony search algorithm with cuckoo search for global numerical optimization[J],” SOFT COMPUT, vol. 20, no. 1, pp. 273-285, 2016. Article (CrossRef Link).

[37] Wang, G., Guo, L., Duan, H., Wang, H., "A New Improved Firefly Algorithm for Global Numerical Optimization[J],” Journal of Computational and Theoretical Nanoscience, vol. 11, no. 2, pp. 477-485, 2014. Article (CrossRef Link).
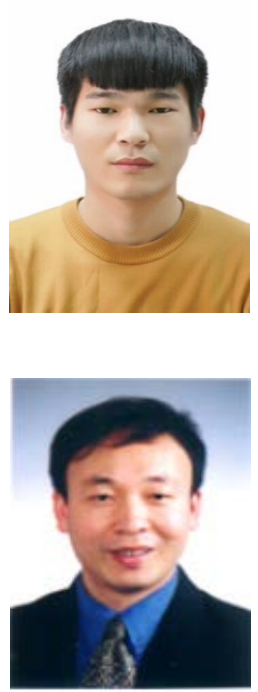

Zhili Chen received his B.Eng. degree in computer science and technology from Shijiazhuang Tiedao University, Shijiazhuang, China, in 2016. He is a postgraduate student in College of Information and Electrical Engineering, China Agricultural University, Beijing, China. His research interests include data mining and personalized recommendation.

Chunjiang Zhao received his M.Sc. degree from Beijing Academy of Agriculture and Forestry Sciences, Beijing, China, in 1988. He received his Ph.D. degree from Beijing Agricultural University, Beijing, China, in 1993. He is a professor at National Engineering Research Center for Information Technology in Agriculture and is an Academician of Chinese Academy of Engineering. He is the director at National Engineering Research Center for Information Technology in Agriculture. His research interests include agricultural information technology and precision agricultural technology system.

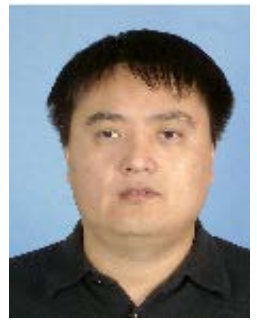

Huarui Wu is a professor at National Engineering Research Center for Information Technology in Agriculture. He is interested in studying Artificial Intelligence. In recent years, he has participated in 18 national and provincial key scientific research projects, and published over 20 academic papers. He got the first prize of Beijing Science and Technology in 2005, and third prize of agricultural technology promotion in 2003.

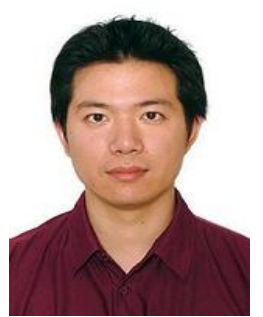

Yisheng Miao received his B.Eng. degree in biomedical engineering from Beihang University, Beijing, China, in 2005. He received his M.Sc. degree in microelectronics and solid-state electronics from Beijing University of Technology, Beijing, China, in 2010. He is currently an associate researcher at National Engineering Research Center for Information Technology in Agriculture. His research interests include wireless sensor networks and intelligent systems in agriculture. 